\title{
Condições de conforto ambiental para usuários: estudo de caso realizado na Biblioteca Central Zila Mamede/UFRN
}

\author{
Luís Cavalcante Fonseca Júnior \\ Graduado em Biblioteconomia pela Universidade Federal do Rio Grande do Norte \\ E-mail: luis_cfj@@hotmail.com \\ Andréa Vasconcelos Carvalho \\ Doutora em Sistemas de Informação e Documentação pela Universidad de Zaragoza, Espanha. \\ Professora do Departamento de Ciência da Informação/UFRN \\ E-mail: andreavascarvalho@gmail.com \\ Daniela Estaregue Alves \\ Mestre em Design em Produção Visual pelo Instituto Superior de Artes, Design e Marketing (IADE), \\ Portugal. Professora do Departamento de Artes/UFRN \\ E-mail:daniesta@gmail.com
}

\begin{abstract}
RESUMO:
Considera que as instalações físicas de uma biblioteca devem proporcionar às pessoas um ambiente confortável para o desenvolvimento de suas atividades, bem como oferecer condições favoráveis à preservação do acervo. Objetiva analisar as condições de conforto térmico, acústico e lumínico da Biblioteca Central Zila Mamede (BCZM) da Universidade Federal do Rio Grande do Norte (UFRN). Aborda as características, a importância, os usuários, os profissionais da informação da Biblioteca Universitária. Informa que a ergonomia ambiental busca propor um ambiente agradável aos usuários, harmonicamente organizado e bem planejado, procurando a interação dos seres humanos (usuários) com os sistemas (bibliotecas). Caracteriza os condicionantes ambientais: térmico, lumínico e acústico. Analisa os dados coletados no questionário realizado com os usuários e no estudo empírico com as medições dos condicionantes pesquisados revelam que há conforto lumínico e não há conforto térmico nem conforto acústico. Assim, conclui que não existe conforto ambiental na BCZM, com algumas ressalvas. Finaliza sugerindo melhorias para o conforto ambiental na Biblioteca Central Zila Mamede e considerando a importância do bibliotecário no contexto da pesquisa em questão.
\end{abstract}

Palavras-chave: Bibliotecas Universitárias. Ergonomia Ambiental. Conforto Ambiental. Biblioteca Central Zila Mamede.

\section{ABSTRACT:}

Considers that the physical facilities of a library should provide people a comfortable environment for the development of their activities, as well as offering favourable conditions for the preservation of the acquis. Objective to analyze the conditions of thermal comfort, acústico and Central Library lumínico Zila Maclean (BCZM) of the Federal University of Rio Grande do Norte (UFRN). Covers the characteristics, the importance, users, information workers of University Library. Reports that the environmental ergonomics search propose a pleasant environment to users, harmonically organized and well-planned, looking for the interaction of human beings (users) with the systems (libraries). Features environmental restrictions: thermal, acoustic and lumínico. Analyzes the data collected in the questionnaire conducted 
with users and the empirical study with measurements of conditions surveyed reveal that there is comfort lumínico and there is thermal comfort or acoustic comfort. Thus, concludes that there is no environmental comfort in BCZM, with some caveats. It's concludes by suggesting improvements to the environmental comfort on Central Library Zila Maclean and considering the importance of the librarian in the context of the research in question.

Key-words: University Libraries. Environmental Ergonomics. Environmental Comfort. Central Library Zila Mamede.

\section{INTRODUÇÃO}

A capacidade que uma biblioteca tem em aproximar pessoas e desenvolver processos, oferecendo produtos e serviços de informação e estimulando a produção do conhecimento, torna-a um espaço de informação e interação essencial na sociedade. Contudo, a percepção do valor da biblioteca se modifica, atualmente, pois cresce nela a penetração das novas tecnologias da informação e comunicação - ponto importante a ser considerado quanto à discussão em relação ao seu espaço físico.

De imediato, traduzimos espontaneamente que o espaço físico construído de uma biblioteca é diferente dos demais, uma vez que possibilita informação e conhecimento. Genuinamente é um lugar de pronunciamento do saber, da conservação e da pesquisa. Além disso, a biblioteca deve refletir em seu exterior o que há dentro dela, para que suas especificidades estimulem as pessoas a entrar em seus prédios, para utilizarem de seus serviços (BARBALHO, 2012). Para tal, faz-se necessário um bom condicionamento ambiental, tanto para seu acervo quanto para a comunidade de usuários e colaboradores que dele fará uso.

A falta de uma boa estrutura física, com iluminação inadequada, climatização inapropriada, mobiliários velhos, falta de manutenção e estruturação ergonômica ajustada resulta em um mau uso dos equipamentos e interfere negativamente no desempenho intelectual do usuário, além dos prejudicar o acervo.

Nesse sentido, é necessário haver um bom planejamento em todas as instalações do edifício. Ele deve levar em consideração as necessidades humanas físicas e psicológicas, bem como também as características dos materiais do acervo geral. Preferencialmente, as edificações para bibliotecas devem ser 
construídas para constituir uma unidade de informação com ótimo espaço, bem arejada, de fácil acesso e que colabore para uma ampliação futura com qualidade e praticidade aos seus usuários. Em muitos casos, porém, as bibliotecas são improvisadas em espaços pequenos, que não permitem mobilidade em seu acervo, apresentando problemas de acessibilidade ao seu usuário.

Além disso, alguns fatores ergonômicos antes mencionados influenciam para o desgaste da biblioteca. Barros (2012) relata que o dimensionamento e a dedicação no planejamento são fundamentais para a elaboração de um bom projeto e excelente produto final. Dessa forma, o desgaste gerado pela falta de uma boa estrutura, que ofereça uma boa climatização, iluminação, acústica e acomodação para acervo, usuários e servidores é sentido negativamente, evidenciando a necessidade imperativa de qualidade, funcionalidade e conforto numa biblioteca.

A partir dessa constatação é que este artigo tem por objetivo geral analisar as condições de conforto térmico, acústico e lumínico da Biblioteca Central Zila Mamede (BCZM), da Universidade Federal do Rio Grande do Norte (UFRN). Ele tem, ainda, como objetivos específicos identificar a percepção dos usuários da referida biblioteca em relação à existência de conforto ambiental e dos seus valores térmicos, acústicos e lumínicos.

Tal pesquisa foi desenvolvida em 2012, estimulada e motivada pela inexistência, por parte da maioria das organizações, de uma preocupação em relação às condições de conforto ambiental. Outro fator determinante é a existência de poucos estudos, na área da Biblioteconomia, que abordem o tema. A grande maioria destes estudos, quando existem, é realizada por profissionais de outras áreas, como a Engenharia e a Arquitetura. E eles dificilmente são aplicados a unidades de informação.

O tema é muito atual, e a BCZM ainda apresenta grandes necessidades de "confortabilidade" ambiental. Assim, consideramos que esta pesquisa pode contribuir para aumentar a consciência sobre a importância de se ter uma maior adequação dos espaços, além de medir as condições de confortabilidade na Biblioteca Central Zila Mamede, apresentando dados reais.

\section{ESTRUTURA FÍSICA PARA BIBLIOTECAS UNIVERSITÁRIAS}


Percebe-se que há uma quantidade incalculável de informações geradas nos dias atuais. As constantes transformações nas formas de comunicação, principalmente devido ao avanço das tecnologias da informação, geram mudanças culturais e sociais que acarretam no crescimento exponencial dos fluxos de informações e no surgimento de novas fontes e espaços informacionais.

Não obstante a propulsão de ferramentas tecnológicas e a emergência dos sistemas digitais e virtuais de disseminação e aquisição de informação, as bibliotecas ainda se mantém como um ambiente diferenciado para aprendizagem e assimilação de conhecimento.

Segundo o Glosario $A L A$ (1988, p. 360) o conceito de Biblioteca Universitária (BU) refere-se a uma "Biblioteca estabelecida, mantida e administrada por uma Universidade para cobrir as necessidades de informação de seus estudantes e apoiar seus programas educativos, de investigação e demais serviços." Assim, devem compartilhar de posicionamentos e ideias da sua respectiva universidade, e estabelecer sua missão a partir das decisões da entidade de ensino. Ela tem que ser mais que mero recinto de leitura, ou deposito de livros, forjando-se enquanto um espaço cultural de múltiplos usos, aprazível aos olhos, onde as pessoas se sintam bem, satisfeitas.

Uma biblioteca universitária deve contemplar a ideia de oferecer conforto ambiental para seus usuários. E sobre isso, Faulkner-Brown (1999) apresenta alguns fatores que refletem bem o que se faz necessário num projeto desta natureza:

a) layouts flexíveis, adaptados de acordo com a estrutura e os serviços, sendo fáceis de modificar;

b) facilitar a circulação dos leitores, do pessoal e do acervo;

c) acessível do exterior para o interior do prédio e da entrada para todas as partes do prédio, com um plano global que necessite o mínimo de direções complementares;

d) permitir o crescimento futuro com o mínimo transtorno;

e) variado na sua oferta de espaços para o leitor, oferecendo ampla liberdade de escolha;

f) organizado para oferecer máximo conforto entre acervo e leitores;

g) confortável para promover a utilização eficaz;

h) constante nas condições ambientais para a preservação dos materiais da biblioteca; 
i) econômico para ser construído e mantido com recursos mínimos, tanto financeiros quanto pessoal (FAULKNER-BROWN, 1999).

Recomenda-se que toda a área deixe espaço livre para instalação futura de estantes, em decorrência da expansão do acervo; além disso, os livros não podem ficar tão apertados para que possam ser arejados; espaço livre entre as estantes de no mínimo $1,20 \mathrm{~cm}$, por questões de mobilidade e conforme a NBR 9050 (ABNT, 2004) inclusive para os usuários de cadeiras de rodas (RIBEIRO, 2006).

Neufert (2013) vai além, ao afirmar que para as áreas destinadas ao acondicionamento dos materiais monográficos devem seguir tais orientações:

\begin{abstract}
A profundidade ou largura corrente das prateleiras, em estantes duplas, é de $72 \mathrm{~cm}$; o comprimento $100 \mathrm{~cm}$. [...] para aproveitar compartimentos de pédireito elevado usam-se estantes mais altas servidas por escadotes mais altas servidas por escadotes rolantes ou por galeiras [...] largura de corredores entre estantes de bibliotecas muito frequentadas $85 \mathrm{~cm}$. (NEUFERT, 2013, p. 262, grifo do autor).
\end{abstract}

A carência de um espaço físico bem delineado, com uma organização bem elaborada, interfere diretamente nos usuários e nos funcionários da biblioteca, podendo ser a causa de conflitos e relacionamentos difíceis, baixa produtividade, baixa qualidade de atendimento, alta rotatividade de funcionários e baixa frequência de usuários (ALMEIDA, 2000, p. 88).

As áreas para cada setor devem ser bem divididas, de tal maneira que possibilite maior dinamização do trabalho, favoreça a maior rapidez nas ações. Os revestimentos de pisos, segundo Trinkley (2001), devem atribuir não somente o conforto, mas também a preservação do ambiente.

Dessa maneira, os pisos não devem exalar nenhum poluente nocivo; não contribuir para a poluição geral da biblioteca; não favorecer a infestação por insetos; sendo impermeáveis ou pelo menos resistentes à água; a prova de fogo, autoextinguível e de fácil limpeza. Os projetos de edificações definem o grau de penetração da energia solar e a influência do calor radiante no edifício. $O$ tipo de isolamento que será feito, principalmente da cobertura, tem uma grande influência na troca de calor entre a edificação e o ambiente externo (IIDA, 2005). Dessa forma confirmasse as perspectivas sobre soluções de conforto ambiental em bibliotecas, descritas por Cordeiro (2015, p. 112) quando o autor afirma que "muitos arquitetos 
têm privilegiado composições proporcionando a presença da natureza em bibliotecas reforçando o discurso ecológico do homem contemporâneo".

É recomendável que essa cobertura tenha baixo custo de manutenção, e que possua assistência técnica local, caso haja necessidade de reparos futuros. $A$ intenção evitar infiltrações, entre outros agentes que causem danos ao acervo e aos usuários de maneira geral (TRINKLEY, 2001).

O mobiliário e o acesso aos ambientes devem ser adaptados e sinalizados, para que qualquer pessoa consiga se movimentar de forma livre, segura e independente. Diante do exposto, o layout destaca-se como um elemento essencial na acessibilidade da biblioteca, visto que diz respeito à disposição física de materiais, móveis e equipamentos em um ambiente, de forma a facilitar e aperfeiçoar os fluxos existentes, racionalizando o aproveitamento dos espaços e dos recursos materiais disponíveis. De acordo com Cury (2012, p. 36):

\footnotetext{
Layout corresponde ao arranjo dos diversos postos de trabalho nos espaços existentes na organização, envolvendo além da preocupação de melhor adaptar as pessoas ao ambiente de trabalho, segundo a natureza da atividade desempenhada, a arrumação dos móveis, máquinas, equipamentos e matérias primas.
}

Ao depararmos com um assunto que visa propor as melhores condições possíveis para os usuários realizarem suas pesquisas e estudos, faz-se necessário o conhecimento sobre ergonomia, área que visa estabelecer normas para melhorar a qualidade de vida do homem, através da intervenção de vários componentes, entre eles os condicionantes ambientais como temperatura, umidade, acústica, ventilação e iluminação. A seguir, serão apresentados aspectos teóricos referentes a essas características.

\subsection{ERGONOMIA}

A ergonomia surgiu em 1949, na Inglaterra, quando alguns cientistas e pesquisadores se reuniram para abordar assuntos que ligavam o ser humano e o trabalho, de acordo com suas particularidades e complexidades. Na segunda reunião do grupo, em 1950, foi proposto o neologismo Ergonomia, onde ergo (do grego ergon), significa trabalho e nomos (também de origem grega), que significa regras, 
normas, leis naturais (IIDA, 2001, p.5). A Associação Brasileira de Ergonomia (ABERGO) adota a definição oficial proposta, em agosto de 2000, pela Associação Internacional de Ergonomia (IEA):

\begin{abstract}
A Ergonomia (ou Fatores Humanos) é uma disciplina científica relacionada ao entendimento das interações entre os seres humanos e outros elementos ou sistemas, e à aplicação de teorias, princípios, dados e métodos a projetos a fim de otimizar o bem estar humano e o desempenho global do sistema. Os ergonomistas contribuem para o planejamento, projeto e a avaliação de tarefas, postos de trabalho, produtos, ambientes e sistemas de modo a torná-los compatíveis com as necessidades, habilidades e limitações das pessoas. (ABERGO, 2012).1
\end{abstract}

Percebe-se que a ergonomia vai muito além de propor melhores condições de trabalho para um determinado grupo de pessoas. Karwowski (2006) descreve que a ergonomia vem evoluindo, e se consolidando como uma disciplina que se concentra na natureza humana (artefatos, interações), e apresenta uma visão agregada para a ciência, engenharia, design, tecnologia e sistemas de gestão de recursos humanos, com uma gama de produtos naturais e artificiais, processos e ambientes.

Esta pesquisa, a propósito do exposto acima, está centrada na ergonomia ambiental, na interação entre biblioteca e usuários. Ela busca propor um ambiente agradável aos usuários, harmonicamente organizado e bem planejado, misturando cores e mobiliário que gerem um ambiente prazeroso e que inspire positividade, seja para que as pessoas passem horas no lugar ou só alguns minutos (PRADO, 2003).

\title{
2.1.1 Conforto Térmico (Temperatura, Umidade e Ventilação)
}

Certamente o clima local, de cada cidade ou região, requerer uma atenção a mais no planejamento do espaço a ser construído ou modificado, pois, além de promover melhor sensação térmica nos usuários, também condicionará uma melhor preservação do acervo. Grandjean e Kroemer (2005) revela que atividades realizadas sob o calor em excesso provoca cansaço e sonolência, e reduz a prontidão de resposta, aumentando a tendência a falhas, ocasionando a diminuição da atenção, e principalmente da concentração para o trabalho intelectual.

\footnotetext{
${ }^{1}$ Documento eletrônico não paginado.
} 
Recomenda-se que as características térmicas de temperatura, umidade e ventilação devem ser planejadas ao mesmo tempo, para que não ocorram oscilações. Aconselha-se práticas como a abertura de janelas num determinado horário do dia; uso de ventiladores e aparelhos de condicionamento de ar (com uma boa manutenção e limpeza de ordem frequente); e ações que promovam a renovação do ar no ambiente, para a evaporação do calor no local. Além disso, a utilização de um higrômetro, que mede a umidade relativa do ar, e um termohigrômetro, que mede a temperatura e a umidade, servem para melhor controle térmico, além de um desumidificador, para retirada da umidade do ambiente (RIBEIRO, 2006).

De acordo com a NR17/Ergonomia (BRASIL, 1990), o índice de temperatura efetiva deve estar entre $20^{\circ} \mathrm{C}$ e $23^{\circ} \mathrm{C}$, a velocidade do ar não pode ser acima de 0,75 $\mathrm{m} / \mathrm{s}$, e a umidade relativa do ar não deve ser abaixo de $40 \%$, oferecendo-se condições térmicas agradáveis aos usuários da biblioteca. lida (2005) revela que existe uma zona de conforto térmico que:

[...] é delimitada entre as temperaturas efetivas de 20 a $24 \stackrel{\circ}{ } \mathrm{C}$, com umidade relativa de 40 a $80 \%$, com uma velocidade do ar moderada, da ordem de 0,2 $\mathrm{m} / \mathrm{s}$ [...]. As diferenças de temperatura (gradiente térmico) presentes no mesmo ambiente não devem ser superiores a $4^{\circ} \mathrm{C}$. Essa zona se refere ao organismo adaptado ao calor. Nos países temperados, durante o inverno, com o organismo adaptado ao frio, essa zona de conforto situa-se entre 18 e 22 ㅇ p para a mesma taxa de umidade e velocidade do vento. (IIDA, 2005, p. 499).

Vale ressaltar que por mais que se busque o conforto humano, não se deve deixar de lado a concepção de preservação do acervo, chamada por Trinkley (2001) de "zona de conforto da coleção". O autor postula algumas ações para não haver tanto desgaste e interferência da climatização no acervo:

\footnotetext{
Manutenção de uma UR (umidade relativa) entre 45 e $55 \%$ por todo ano, permitindo flutuações sazonais entre os dois valores extremos, mas minimizando as flutuações diárias; Manutenção da temperatura entre 18 e $24^{\circ} \mathrm{C}$ por todo o ano, permitindo flutuações sazonais entre os dois valores externos, mas minimizando as flutuações diárias; Um projeto de filtragem para remover pelo menos $50 \%$ das partículas em suspensão utilizando-se o Dust spot efficiency test da ASHRAE; Um projeto de filtragem gasosa para manter padrões de preservação por toda a instalação, ou a utilização da filtragem por via aérea, conforme seja necessário; Fornecimento de uma ventilação adequada para evitar bolsões de ar estagnado, zonas mortas nas extremidades dos corredores e cantos das áreas de armazenamentos de livros e problemas similares condizentes com o desenvolvimento de mofo. (TRINKLEY, 2001, p. 56).
} 


\subsubsection{Conforto Acústico}

Um ótimo ambiente de estudo tem que apresentar condições de conforto acústico favoráveis aos seus usuários. Segundo a NBR 10152 (ABNT, 2000), os índices considerados aceitáveis de ruídos em bibliotecas estão entre 35 e $45 \mathrm{~dB}(\mathrm{~A})$.

Num ambiente como a biblioteca, normalmente os usuários mantém um alto nível de concentração para compreender, gerar e expressar idéias, com isso, todo e qualquer ruído em alta intensidade interfere negativamente. Geralmente as conversas paralelas e até mesmo as atividades rotineiras da biblioteca (inserção dos livros nas prateleiras, atendimento ao usuário) causam ruídos que interferem no desempenho intelectual dos usuários, podendo ser controlados.

Para a resolução de tais problemas, Ribeiro (2006) aponta algumas soluções, como identificar as fontes externas e internas de ruído; e classificá-las como ruído aéreo ou de impacto. Salas de estudo em grupo e individual; pisos de características flutuantes, para amenizar os ruídos provenientes do arrastar de móveis e passos; materiais que absorvam os ruídos dos dutos e tubulações; assim como um isolamento acústico com o meio exterior.

\subsubsection{Conforto Lumínico}

A luz favorece ao usuário boa localização e identificação de materiais, e auxilia (dependendo da intensidade) em atividades de leitura e compreensão textual.

Segundo a NBR 5413 (ABNT, 1992) os níveis de iluminação adequada em lux para bibliotecas se dividem em sala de leitura, com valores de 300 a 750 lux, média de 500 lux e recinto das estantes, que seriam os espaços reservados ao acervo, com valores de 200 à 500 lux, média de 300 lux, pois é necessário considerar que os diferentes espaços de uma biblioteca e as diferentes atividades desenvolvidas requerem iluminação diferenciada. Santos (2012) confirma que a iluminação deve ser definida como componente que acomoda conforto aos usuários e a equipe da biblioteca, proporcionando a absorvimento de dados disponíveis em vários tipos de suportes. Além disso, a iluminação natural deve ser promovida e elevada nas bibliotecas, por contribuir na conservação energética, beneficia a 
manutenção de uma luz variável que satisfaz a natureza psíquica do homem. (CORDEIRO, 2015).

\section{PROCEDIMENTOS METODOLÓGICOS}

Este trabalho é fruto de uma pesquisa empírica e sua abordagem é quantiqualitativa. Exploratória e descritiva, a pesquisa deverá proporcionar maior familiaridade com o tema tratado, tornando-o explícito. Consiste em descrever as características da Biblioteca Central Zila Mamede, relacionando seu ambiente físico à percepção que dele fazem os seus usuários. Nesta pesquisa utilizou-se uma abordagem quantitativa, pois, segundo Ethos (2012), ela é apropriada para medir opiniões, atitudes e preferências dos questionados. Mas ela também possui igualmente uma abordagem qualitativa, pois foram interpretadas de forma global e individualizada as respostas obtidas, e, a partir disso, analisados os condicionantes ambientais da BCZM.

Os procedimentos metodológicos adotados incluem pesquisa bibliográfica e de campo. A pesquisa bibliográfica envolve o levantamento bibliográfico de livros, periódicos, estudos de casos e artigos científicos. Já a pesquisa de campo consistiu na realização de um estudo empírico detalhado com a medição dos condicionantes ambientais - térmico, acústico e lumínico - da Biblioteca Central Zila Mamede UFRN, e aplicação de questionários para comunidade de usuários. O estudo realizado caracteriza-se também como um estudo de caso, pois se delimita a estudar detalhadamente uma única instituição. (GIL, 2002).

A missão da BCZM é fornecer aos seus usuários suporte informacional nos mais variados suportes, a fim de atender as atividades de ensino, pesquisa e extensão da UFRN. Ela possui em sua estrutura física, uma área de 4.937,32 $\mathrm{m}^{2}$, videoteca com 30 lugares, auditório com capacidade de 140 lugares, hall para exposições, sala de autores norte-rio-grandense, sala de máquinas leitoras, copiadoras e de Multímeios, uma sala climatizada de estudo individual com 36 cabines, seis salas para estudo em grupos, cantina e jardins internos. (EUGÊNIO, 2011).

A Biblioteca Central Zila Mamede inaugurou no ano de 2010 um prédio anexo, denominado "Anexo da BCZM", como parte de seu projeto de ampliação. O novo edifício tem área física igual a $3.587,97 \mathrm{~m}^{2}$, totalmente climatizada, com mini 
auditório com 50 lugares, hall para Exposições, a sala de obras raras que foi transferida para o anexo, laboratório de Informática com 20 máquinas, laboratório de acessibilidade, ambiente com 89 cabines para estudo individual, mesas para estudo em grupo com 75 lugares, junto ao acervo, quatro tótens para acesso ao catálogo on-line. (BIBLIOTECA CENTRAL ZILA MAMEDE, 2012).

A BCZM possui um acervo com mais de 300 mil exemplares, de todas as áreas do conhecimento que abrange os cursos da UFRN. Apresenta um fluxo de empréstimos e renovações em torno de 25 mil por mês, entretanto, esse quantitativo cai para o patamar dos oito mil nos períodos de recesso. (BIBLIOTECA CENTRAL ZILA MAMEDE, 2012).

Os serviços oferecidos pela biblioteca são: consulta local, empréstimo domiciliar, empréstimo entre bibliotecas, comutação bibliográfica, orientação bibliográfica, pesquisa bibliográfica, levantamento bibliográfico, normalização dos documentos, catalogação na fonte, ISBN, ISSN, direitos autorais, visitas programadas, acesso à internet, reprografias de documentos, reserva de espaço para evento. As principais atividades realizadas pelos usuários são empréstimo e devolução de livros, consulta de exemplares e estudos individuais.

A amostragem da pesquisa, formada pelo universo dos usuários da BCZM, pretendeu-se analisar os aspectos condicionantes do ambiente da BCZM relacionando-os às características referentes à temperatura, acústica e luminosidade do ambiente.

Diante da população de aproximadamente dois mil usuários diários da Biblioteca (BIBLIOTECA CENTRAL ZILA MAMEDE, 2012), optou-se por entrevistas apenas nos setores de circulação (prédio antigo e anexo) e de coleções especiais do prédio antigo. Foram realizadas 30 (trinta) entrevistas. $60 \%$ dos sujeitos entrevistados são do gênero (sexo) feminino. Em relação à faixa etária, $70 \%$ têm idade entre 20 e 29 anos; 10\% têm idade até 20 anos; 7\% apresentam idade entre 30 e 39 anos; o mesmo vale para os que têm 50 anos ou mais; os outros $6 \%$ representam o quantitativo dos que tem idade entre 40 e 49 anos. Sobre a formação/vinculação dos informantes, consta que 73\% são de alunos da UFRN; $10 \%$ são de ex-alunos da referida instituição de ensino; 7\% são de professores da UFRN, e outros $7 \%$ de servidores desta universidade; outros $3 \%$ representam o quantitativo dos que nunca tiveram vinculo algum com a UFRN. As opções de ex-aluno e exprofessor teve $0 \%$ de sujeitos. 


\subsection{PROCEDIMENTOS INSTRUMENTAIS E COLETA DE DADOS}

A coleta de dados foi realizada através de dois procedimentos distintos: a) aplicação de questionários a uma amostra de usuários; e b) um estudo empírico de medições dos condicionantes ambientais na instituição. Ocorreram, respectivamente, nos dias 29 de novembro (entre as 09h30min e 10h30min da manhã), e 06 de dezembro (14h30min e 15h30min) de 2012, realizados pelo pesquisador. Tal questionário foi aplicado à comunidade de usuários, e foi estruturado com perguntas fechadas, totalizando 19 indagações. Ambos instrumentos de coleta de dados foram baseados nas propostas de Ribeiro (2006) e Vasconcelos et al. (2009). As indagações foram referentes a temperatura, umidade, ventilação, acústica e luminosidade em bibliotecas, além de outros fatores, como mobiliário, sinalização e segurança.

Foram extraídos três valores medidos em três pontos distintos dentro de um mesmo ambiente, para se ter uma média sobre a referida unidade. Foram feitas duas medições em cada prédio, antigo e anexo. Para as medições sobre conforto térmico foram medidas as unidades de temperatura em grau Celsius $\left({ }^{\circ} \mathrm{C}\right)$, ventilação em metros por segundo $(\mathrm{m} / \mathrm{s})$ e umidade, que é expressa em porcentagem $(\%)$; para medição de conforto acústico foi medido o ruído em $\mathrm{dB}(\mathrm{A})$ e para conforto lumínico foi medida a luminosidade no ambiente, em lux. Para as medições das unidades relacionadas a conforto térmico foi utilizado o Termo-Higro-Anemômetro Digital Pórtatil-Modelo Thar-185 da Instrutherm.

Figura 1 - Termo-Higro-Anemômetro

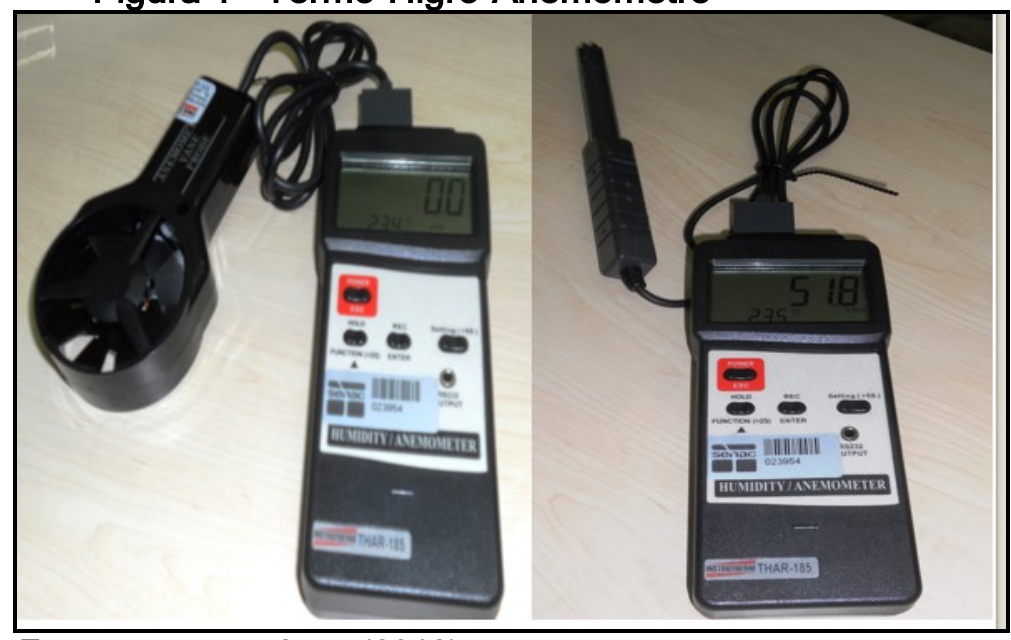

Fonte: autoria própria (2012).

Rev. Inf. na Soc. Contemp., Natal, RN, v.1, n.3, jul/dez., 2017 
Na medição de ruído foi usado o Decibelímetro - Medidor de Nível de Pressão Sonora-Modelo Dec-460 da Instrutherm, e na medição da luminosidade usou-se o Luxímetro Digital Lux Meter - Modelo Itld 260 da Instrutemp - Mini Medidor de Luz.

Figura 2 - Decibelímetro

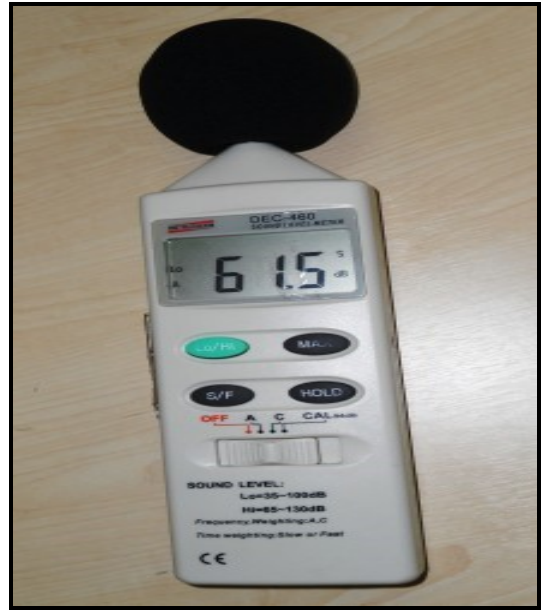

Fonte: autoria própria (2012).
Figura 3 - Luxímetro

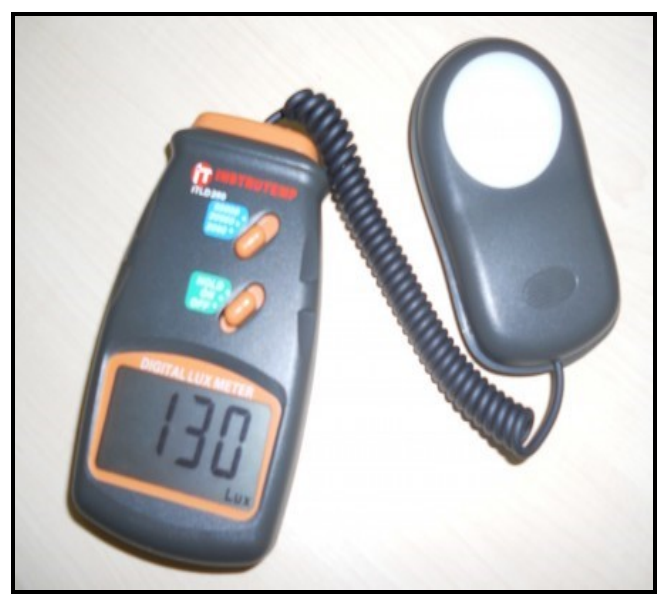

Fonte: autoria própria (2012).

\section{ANÁLISE E DISCUSSÃO DOS RESULTADOS: EXISTE CONFORTO AMBIENTAL NA BCZM?}

As condições de conforto no ambiente da BCZM estão indicadas adiante, onde os dados e conclusões da pesquisa encontram-se expostos. De início analisouse a percepção dos usuários da biblioteca. Isso a partir dos questionários aplicados a eles. Os resultados da avaliação empírica dos condicionantes ambientais, no intuito de obter dados objetivos sobre eles, a fim de comparar com os valores ideais, para saber se existe o conforto ambiental na BCZM, estão dispostos logo em seguida.

\subsection{PERCEPÇÃO DOS USUÁRIOS}


$\mathrm{Na}$ sequência iremos analisar os dados coletados sobre os condicionantes fazendo uma comparação entre os dois prédios da biblioteca, o antigo e o anexo (novo).

Sobre conforto térmico, quase $50 \%$ dos usuários da BCZM responderam que o ambiente no prédio antigo era quente. Vale ressaltar que outro $20 \%$ o consideram muito quente. Por outro lado, no ambiente no prédio anexo, 60\% consideram-no fresco. Outros $27 \%$ consideram-no frio. Tal discrepância explica-se pelo fato do prédio antigo não ser climatizado, ao contrário do novo. A ventilação no prédio antigo é feita com ventiladores de pedestal, e no prédio anexo com aparelhos de ar condicionado, conforme mostram as figuras abaixo:

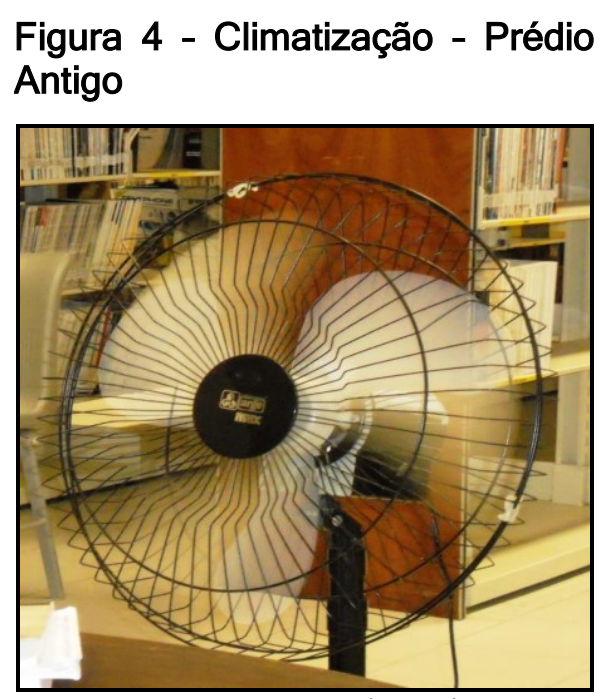

Fonte: autoria própria (2012).
Figura 5 - Climatização Prédio Anexo

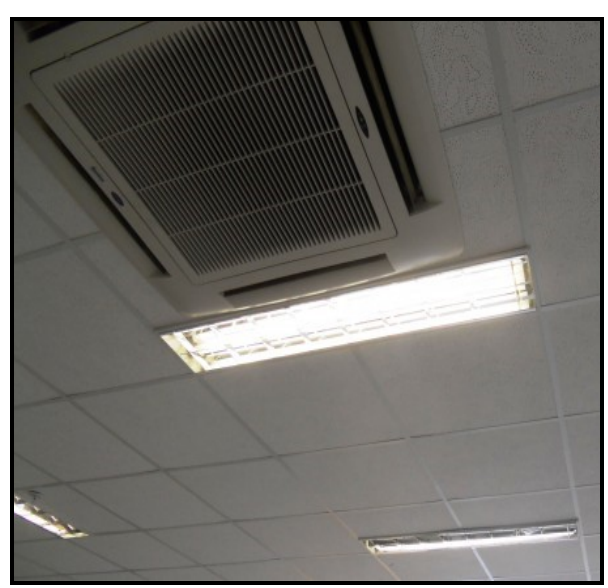

Fonte: autoria própria (2012).

Em relação ao conforto lumínico, o nível de iluminação do prédio antigo é considerado "bom" para $60 \%$ dos usuários e "ótimo" para $27 \%$. Uma avaliação positiva, portanto. Entretanto, para o prédio anexo os resultados são diferentes. $40 \%$ dos entrevistados considera a iluminação deste prédio apenas "regular". Há, então, maior crítica sobre o prédio anexo quanto à questão, ainda que nele haja paredes de vidro que fornecem incidência de luz ainda maior do que no prédio antigo. Inferimos disso a probabilidade de que a iluminação no prédio anexo seja excessiva, provocando desconforto nos seus usuários.

Em relação as variações sobre conforto acústico, $60 \%$ dos usuários apontaram que o nível de ruído é considerado é "baixo" no prédio antigo; $54 \%$ tem a mesma opinião para o prédio anexo. Conversas paralelas entre usuários ou 
funcionários, uso de aparelhos eletrônicos, computadores, carrinho dos livros do setor de circulação, ou até mesmo ruídos externos, geralmente são causados pelo transito que existe nas proximidades, ou por construção nas adjacências, foram fatores causadores de ruídos apontados pelos usuários.

\subsection{RESULTADOS DA AVALIAÇÃO EMPÍRICA DOS CONDICIONANTES AMBIENTAIS}

Os dados expostos na Tabela 1 foram levantados no ambiente do $1^{\circ}$ andar, no setor de Coleções Especiais no prédio antigo. Percebe-se que a temperatura está bem elevada para os valores ideais, tendo uma média de $29,5 \circ \mathrm{C}$, quando não poderia passar dos $24^{\circ} \mathrm{C}$. A ventilação teve uma variação nula de $0,0 \mathrm{~m} / \mathrm{s}$, e para um ambiente que apresenta tal temperatura, seria interessante haver uma ventilação efetiva.

A umidade relativa do ar girou em torno $61,5 \%$. Não ultrapassou o valor máximo de $80 \%$, porém se houvesse maior ventilação no ambiente, a qualidade do ar seria ainda melhor. $O$ nível de ruído teve media de $55,3 \mathrm{~dB}(\mathrm{~A})$, passando do limite ideal de $45 \mathrm{~dB}(\mathrm{~A})$. Isso se deve as conversas constantes entre usuários, ao ventilador que estava no ambiente e ao trânsito de veículos do lado de fora da biblioteca. Entretanto, a luminosidade obteve um grau considerado bom de 468,7 lux, chegando bem próximo da margem média de 500 lux.

Tabela 1 - Medição Empírica 1 - Prédio Antigo

AMBIENTE 1 - PRÉDIO ANTIGO

\begin{tabular}{l|c|c|c|c|c}
\hline & Valor 1 & Valor 2 & Valor 3 & Média & Ideal \\
\hline Temperatura & 29,1 & 29,7 & 29,7 & $\mathbf{2 9 , 5}$ & de 20ㄷ à 24ㅇ \\
\hline Ventilação & 0 & 0 & 0 & 0,0 & máx. de $0,75 \mathrm{~m} / \mathrm{s}$ \\
\hline Umidade & 62,3 & 61,2 & 61,1 & 61,5 & min. de $40 \%$ \\
\hline Ruído & 53 & 55 & 58 & 55,3 & 35 e $45 \mathrm{~dB}(\mathrm{~A})$ \\
\hline Luminosidade & 435 & 499 & 472 & $\mathbf{4 6 8 , 7}$ & média de 500 lux
\end{tabular}

Fonte: autoria própria (2012).

Para a constatação dos valores presentes na Tabela 2, o ambiente térreo, no setor de circulação, do prédio antigo foi o local indicado para a aplicação das medições empíricas. Constata-se que a temperatura obtém um valor elevado de $29,1^{\circ} \mathrm{C}$, 
passando do limite ideal. As unidades de ventilação e umidade mantêm valores equilibrados, porém a ventilação poderia ser mais efetiva, que melhoraria bastante o equilíbrio térmico. O ruído também obteve valores elevados, como media de 53,6 $\mathrm{dB}(\mathrm{A})$, passando do nível imaginado. A luminosidade manteve um bom nível, como no primeiro ambiente avaliado, e ficou com média de 471 lux.

Tabela 2 - Medição Empírica 2 - Prédio Antigo

\begin{tabular}{l|c|c|c|c|c}
\hline \multicolumn{7}{c}{ AMBIENTE 2 - PRÉDIO ANTIGO } \\
\hline & Valor 1 & Valor 2 & Valor 3 & Média & Ideal \\
\hline Temperatura & 29,2 & 29,2 & 29 & $\mathbf{2 9 , 1}$ & de 20ㄷ à 24으 \\
\hline Ventilação & 0 & 0 & 0 & 0,0 & máx. de $0,75 \mathrm{~m} / \mathrm{s}$ \\
\hline Umidade & 64,7 & 63,5 & 64,8 & $\mathbf{6 4 , 3}$ & min. de $40 \%$ \\
\hline Ruído & 55,5 & 52,2 & 53 & $\mathbf{5 3 , 6}$ & 35 e 45 dB $(\mathrm{A})$ \\
\hline Luminosidade & 606 & 402 & 405 & $\mathbf{4 7 1 , 0}$ & média de 500 lux \\
\hline
\end{tabular}

Fonte: autoria própria (2012).

Para as medições que constam na Tabela 3 , foi utilizado o ambiente do $1 \stackrel{0}{ }$ andar no prédio anexo, próximo a escada de acesso. O valor médio da temperatura foi de 24,5ㄷ , bem próximo do ideal, e ainda requer uma melhora, embora não venha interferir tanto. A ventilação obteve média de $0,0 \mathrm{~m} / \mathrm{s}$. Neste caso, por ser um ambiente fechado e climatizado, a ventilação fica difícil de acontecer. A umidade teve media de $54,7 \%$, bem menor em comparação com as medias nos ambientes do prédio antigo, valor este bastante positivo. O nível de ruído teve media de 56,9 dB(A), ainda mais elevado que no prédio antigo. Provavelmente em decorrência do número maior de pessoas no ambiente, e em conversas constantes. Quanto à luminosidade, a avaliação apontou que a média é bastante positiva, obtendo 505 lux em média, um pouco maior que o ideal.

Tabela 1 - Medição Empírica 3 - Prédio Anexo

\begin{tabular}{l|c|c|c|c|c}
\hline \multicolumn{7}{c}{ AMBIENTE 1 - PRÉDIO ANEXO } \\
\hline & Valor 1 & Valor 2 & Valor 3 & Média & ideal \\
\hline Temperatura & 24,6 & 25 & 23,8 & $\mathbf{2 4 , 5}$ & de 20ㄷ à 24ㅇ \\
\hline Ventilação & 0 & 0 & 0 & $\mathbf{0 , 0}$ & máx. de $0,75 \mathrm{~m} / \mathrm{s}$ \\
\hline Umidade & 54,3 & 55,2 & 54,7 & $\mathbf{5 4 , 7}$ & min. de $40 \%$ \\
\hline Ruído & 57,7 & 60,3 & 52,7 & 56,9 & 35 e $45 \mathrm{~dB}(\mathrm{~A})$ \\
\hline Luminosidade & 723 & 422 & 370 & $\mathbf{5 0 5 , 0}$ & média de 500 lux \\
\hline
\end{tabular}

Fonte: autoria própria (2012). 
A avaliação constante na Tabela 4 foi feita no $2^{\circ}$ andar do prédio anexo, e obteve os seguintes valores: a temperatura de $22,4^{\circ} \stackrel{ }{ } \mathrm{C}$, dentro do limite ideal, única média de temperatura que ficou dentro do limite ideal. A ventilação obteve variação de $0,0 \mathrm{~m} / \mathrm{s}$. A umidade obteve uma boa média de $57 \%$. O nível de ruído teve media de 50,50 $\mathrm{dB}(\mathrm{A})$, acima do limite indicado. A luminosidade obteve média de 904,3 lux, acima do recomendável, que é de de 750 lux. Isso se deve ao fato desta avaliação ter sido feita nas mesas que ficam bem próximas as paredes de vidro, onde a incidência de luz é maior.

Tabela 4 - Medição Empírica 4 - Prédio Anexo

\begin{tabular}{l|c|c|c|c|c}
\hline \multicolumn{7}{c}{ AMBIENTE 2 - PRÉDIO ANEXO } \\
\hline & Valor 1 & Valor 2 & Valor 3 & Média & ideal \\
\hline Temperatura & 22,5 & 22,4 & 22,5 & $\mathbf{2 2 , 4 7}$ & de 20C à 24ㄷ \\
\hline Ventilação & 0 & 0 & 0 & $\mathbf{0 , 0}$ & máx. de 0,75 m/s \\
\hline Umidade & 57,2 & 56,3 & 57,5 & $\mathbf{5 7}$ & min. de $40 \%$ \\
\hline Ruído & 49,5 & 51,2 & 50,8 & 50,5 & 35 e $45 \mathrm{~dB}(\mathrm{~A})$ \\
\hline Luminosidade & 900 & 923 & 890 & $\mathbf{9 0 4 , 3}$ & média de 500 lux \\
\hline
\end{tabular}

Fonte: autoria própria (2012).

Diante das percepções dos usuários e da direção e das medições feitas no ambiente todo da biblioteca contata-se que não existe conforto térmico desejado, tendo em vista que os níveis de temperatura variam muito entre os ambientes, e principalmente no prédio antigo, onde não se consegue atingir o limite de $24^{\circ} \mathrm{C}$, valor atribuído por lida (2005), ao buscar uma zona de conforto térmico apropriada aos padrões brasileiros. O autor determinou como ideal a temperatura entre $20^{\circ}$ e $24^{\circ} \mathrm{C}$, com umidade relativa de 40a, e ao mesmo tempo, as diferenças de temperatura em um mesmo ambiente não devem ser superiores a $4^{\circ} \mathrm{C}$. Nas comparações entre os ambientes do prédio antigo com o prédio anexo, essa diferença passa dos 5으. Quando analisados em separado, os prédios apresentam resultados diferentes. Enquanto o anexo obtém valores próximos dos limites ideais, o antigo deixa a desejar em praticamente todas as unidades medidas.

Sobre a acústica constata-se que não existe conforto, tendo em vista os altos níveis de ruído detectado na avaliação empírica que acompanharia se os resultados estariam compatíveis com os índices considerados aceitáveis pela NBR 10152 (ABNT, 2000), que estabelece índice entre 35 e $45 \mathrm{~dB}(\mathrm{~A})$ para bibliotecas. 
Em relação à iluminação, percebe-se que existe conforto lumínico. Por mais que a direção da BCZM reprove a iluminação em alguns momentos, no prédio antigo, a avaliação nos dois prédios, feita pelos usuários é extremamente positiva. $E$ a constatação do estudo empírico que indica variações entre 468,7 lux e 505 lux. Comparados a NBR 5413 (ABNT, 1992), que estabelece valores de iluminância para bibliotecas, com valores de 300 a 750 lux, média de 500 lux para salas de leitura; e recinto das estantes, que seriam os espaços reservados ao acervo, com valores de 200 à 500 lux, média de 300 lux, os níveis estariam dentro dos padrões. Observou-se que foi obtido um valor de 904,3 lux num dos ambientes, porém tem que haver uma relevância, visto que este valor se deve á proximidade das paredes de vidro. A BCZM já tem o entendimento desta situação, e pretende colocar películas para determinadas áreas que tem excesso de incidência de luz.

Portanto, de acordo com os dados obtidos na revisão bibliográfica, nos questionários e entrevista aplicados, e pelo estudo empírico de medições, aponta-se que não existe conforto ambiental na Biblioteca Central Zila Mamede, com ressalvas, visto que o conforto lumínico é positivo e demonstra satisfação por parte dos usuários, e pelo conforto térmico no prédio anexo, que obteve boa avaliação, mas também teve observações negativas sobre ventilação, que não existe no local. Além disso, a iluminação no prédio anexo, por mais que tenha avaliação positiva, carece de algum mecanismo que impeça a forte incidência de luz em alguns locais, e em determinados horários do dia.

\section{CONSIDERAÇÕES FINAIS E RECOMENDAÇÕES}

Em vista os resultados obtidos durante a pesquisa, quando se objetivou analisar as condições de conforto térmico, acústico e lumínico da BCZM, a fim de identificar a percepção dos usuários em relação à existência de conforto ambiental na BCZM, terem se revelado eficazes - um mapeamento sobre tais condicionantes pode ser realizado com sucesso - classificamos que ela - a pesquisa - pode ser de significativa valia à comunidade acadêmica.

Os resultados deste trabalho, nesse sentido, devem servir à comunidade de usuários da biblioteca.

Um fator negativo da pesquisa foi a constatação de nunca ter havido um estudo como este na unidade de informação analisada, tendo em vista que a 
realidade constatada de mal condicionamento ambiental, interfere de forma negativa no andamento dos trabalhos, estudos e pesquisas dos usuários.

Recomendamos que sejam feitas adaptações no prédio antigo para amenizar a sensação de calor no ambiente. Deve-se aumentar a capacidade de ventilação natural e artificial no ambiente, deixando-o mais agradável. Faz-se necessário um estudo ainda mais aprofundado que contemple todas as etapas das variações térmicas, envolvendo as aplicações de correntes e umidade relativa do ar.

No que diz respeito ao conforto acústico, os altos níveis detectados revelam que a BCZM precisa com urgência de uma política de educação de usuários para diminuir as conversas dentro dos ambientes. Entretanto, há outras medidas também ajudariam no isolamento acústico: uso de cadeiras acolchoadas, estantes de MDF revestida com silicone e paredes de gesso acantonado.

Sobre o conforto lumínico, único condicionante a ter avaliação positiva, considera-se que deva existir maior controle de incidência de luz, por parte da equipe da BCZM. Além disso, uma pesquisa mais aprofundada sobre esse condicionante, principalmente em relação às áreas que tem maior exposição aos raios ultravioleta do sol. Sobe as películas que se pretende colocar no prédio anexo, também deve pesquisar sobre o assunto, para saber o melhor material a ser afixado.

De forma geral, avaliamos que estudos e pesquisas como este devem ser constantes na referida instituição, ao menos uma vez por ano. Dessa forma, observar-se-ia o grau de satisfação da comunidade acadêmica em relação ao conforto ambiental, aos seus condicionantes, para que cada vez mais os dados fossem melhorados, até que se atingissem, numa situação ideal, os valores indicados pela literatura da área - observando em mantê-los, em seguida.

\section{REFERÊNCIAS}

ABERGO (Brasil). O que é ergonomia ? [S.I.: s.n.]. Disponível em:

<http://www.abergo.org.br/internas.php?pg=o_que_e_ergonomia>. Acesso em: 07 nov. 2012.

ALMEIDA, Maria Christina Barbosa de. Planejamento de Bibliotecas e Serviços de Informação. 2. ed. Brasília: Briquet de Lemos, 2005.

ARAÚJO, Luis César G. de. Organização, sistemas e métodos e as modernas ferramentas de gestão organizacional. São Paulo: Atlas, 2001. 
ASSOCIAÇÃO Brasileira de Normas Técnicas. NBR 5413: Iluminância de Interiores. Rio de Janeiro, 1992.

NBR 10152: Níveis de ruído para conforto acústico. Rio de Janeiro, 2000.

NBR 9050: Acessibilidade de pessoas portadoras de deficiências a edificações, espaço, mobiliário e equipamentos urbanos. 2. ed. Rio de Janeiro, 2004.

BARBALHO, Célia Regina Simonetti (Org.) et al. As cartografias da biblioteca. In: . Espaços e ambientes para leitura e informação. Londrina: ABECIN, 2012.

BARROS, Maria Helena T. C. de. Arquitetura de bibliotecas: a modelagem proporcionada por estruturas novas, ampliações e reformas. In: BARBALHO, Célia Regina Simonetti (Org.) et al. Espaços e ambientes para leitura e informação. Londrina: ABECIN, 2012.

BIBLIOTECA CENTRAL ZILA MAMEDE (Rio Grande do Norte). Universidade Federal do Rio Grande do Norte. Biblioteca Central Zila Mamede. Disponível em: <http://sisbi.ufrn.br/bczm/>. Acesso em: 02 dez. 2012.

BRASIL. Ministério do Trabalho. Norma regulamentadora de segurança e saúde do trabalhador: NR 17/Ergonomia (117.000-7). Portaria n. 3751, de 23 de nov. de 1990.

CORDEIRO, Vivaldo. Resenha. Revista Brasileira de Biblioteconomia e Documentação, São Paulo, v. 11, n. 1, p. 102-106, jan./jun. 2015.

CURY, Antony. Organização e métodos: uma visão holística. 8. ed. São Paulo: Atlas, 2012.

ETHOS. Compreenda a pesquisa quantitativa. [S.I.: s.n.]. Disponível em: <http://www.ethos.com.br/diferenciais/pesquisaquantitativa.htm>. Acesso em: 19 nov. 2012.

EUGÊNIO, José Edmilson da Silva. Acessibilidade para estudantes com necessidades educacionais especiais: estudo de caso na Biblioteca Central Zila Mamede da Universidade Federal do Rio Grande do Norte. 2011. 52 f. Monografia (Bacharel em Biblioteconomia) - Curso de Biblioteconomia, Departamento de Biblioteconomia, Universidade Federal do Rio Grande do Norte, Natal, 2011.

FAULKNER-BROWN, Harry. Design de Grandes Edifícios para Bibliotecas. In: Instituto Brasileiro de Informação em Ciência e Tecnologia. A Informação: tendências para o novo milênio. Brasília, DF: IBICT, 1999.

GIL, Antônio Carlos. Métodos e técnicas de pesquisa social. 4 ed. São Paulo: Atlas, 2002.

GLOSARIO ALA de Bibliotecologia y Ciencias de la Informacion. Madri: Ediciones Díaz de Santos, 1988. 
GRANDJEAN, E.; KROEMER,K. H. E. Manual de ergonomia: adaptando o trabalho ao homem. 5. ed. Porto Alegre: Bookman, 2005.

IIDA, Itiro. Ergonomia: projeto e produção. 2. ed. São Paulo: Blucher, 2005.

KARWOWSKI, Waldemar. International encyclopedia of ergonomics and human factors. Florida: Taylor \& Francis, 2006.

NEUFERT, Ernst. Arte de projetar em arquitetura. 18. ed. Barcelona: Gustavo Gilli, 2013.

PRADO, Heloisa de Almeida. Organização e administração de bibliotecas. 2. ed. São Paulo: T.A Queiroz, 2003.

RIBEIRO, Cira Adriana Martins. A Biblioteca Central da UFRGS: estudo de suas condições de conforto ambiental. 2006. 61f. Pesquisa (Bacharel em Biblioteconomia), Curso de Biblioteconomia, Faculdade de Biblioteconomia e Documentação, Universidade Federal do Rio Grande do Sul, Porto Alegre, 2006.

SANTOS, Jussara Pereira. Gestão ambiental em bibliotecas: aspectos interdisciplinares sobre ergonomia, segurança, condicionantes ambientais e estética nos espaços de informação. Porto Alegre: Ed. da UFRGS, 2012.

TRINKLEY, Michael. Considerações sobre preservação na construção e reforma de bibliotecas: planejamento para preservação. 2. ed. Rio de Janeiro: Projeto Conservação Preventiva em Bibliotecas e Arquivos: Arquivo Nacional, 2001. 116 p. (Conservação Preventiva em Bibliotecas e Arquivos; 38).

VASCONCELOS, Christianne Soares Falcão e; VILLAROUCO, Vilma; SOARES, Marcelo Márcio. Avaliação Ergonômica do Ambiente Construído: Estudo de caso em uma biblioteca universitária. Ação Ergonômica, v. 4, n. 1, p.5-25, 2009. 